\title{
Correlates Between Health Seeking Behaviour and Health Status; A Cross-Sectional Study Among the Elderly Group in Nigeria
}

\author{
Bolaji Damilola Agboola1*, Joel Olayiwola Faronbi2 $^{2}$
}

${ }^{1}$ Centre for Distance Learning, Obafemi Awolowo University, Ile Ife, Nigeria. Email: bolarjiagboola@gmail.com, Orcid ID: 0000-0001-8795-4912

2Department of Nursing Science, Obafemi Awolowo University, Ile Ife, Nigeria. Email: joelfaronbi@gmail.com, Orcid ID: 0000-0003-2168-5099

*Corresponding author

Received: 02 December 2021

Revised: 05 January 2022

Accepted: 16 January 2022

Published: 18 February 2022

\begin{abstract}
Background: The aim of this study was to examine the correlates between health seeking behavior and health status among the Elderly group in Osun State, Nigeria. Material \& Methods: A cross-sectional study was conducted in Osun State between July-October 2020. A multistage sampling method was used to select 433 people aged 60 years and older. The participants were interviewed face-to-face using a well-structured questionnaire. Both descriptive and inferential statistics was used to analyse data. Results: Findings from the study revealed that majority $(77.8 \%)$ of the respondents had poor health status. Key findings showed that majority $(72.4 \%)$ of respondents had good health seeking behaviour. Furthermore, age $(\mathrm{p}<0.05)$, marital status $(p<0.05)$, educational status $(p<0.05)$ and monthly income $(p<0.05)$ were statistically associated with the health status of the elderly people. Conclusions: An adequate understanding of health seeking behaviour and its correlates with health status especially among the elderly people is needed to improve the health care in Nigeria. Although the elderly people have a good health seeking behaviour, it does not however translate to good health status. Therefore, strategies to improve the health status including improving their financial status should be developed with adequate health literacy. Elderly people should learn the importance of regular health examinations to promote health, prevent diseases, and slow the progress of chronic diseases.
\end{abstract}

Keywords:- Health seeking behavior, elderly people, morbidity pattern, health status, Nigeria.

\section{INTRODUCTION}

Health seeking behaviour has be found as an important component of the overall wellbeing of an individual especially in old age, with declining mental and physical functions.[1] Through health seeking behavior, an individual can take care of their heath whether in a perceived health concern or when facing actual illness. This is most especially needed among the elderly individuals who are 60+ years. According to, [2] the number of individual aged $60+$ years is increasing by $3.2 \%$ every year which is projected to follow a similar trend in years to come. Nigeria being the most populated country in Africa has one of the fastest growing older populations in sub-Saharan Africa.[3] However, this older/elderly people were being faced with divers health challenges including high blood pressure, cardiac problems, diabetes, joint 
Annals of International Medical and Dental Research

E-ISSN: 2395-2822 | P-ISSN: 2395-2814

Vol-8, Issue-2 | March-April 2022

DOI: 10.53339/aimdr.2022.8.2.9

Page no- 52-62 | Section- Research Article (Public Health)

pains, kidney infections, cancer, poor sight and body weakness. [4] According to many of these ailments are chronic and often demand that the individual frequently visit health care centres and in a dire situation administration of intensive care might be required. $[5,6,7]$ Others are not chronic and merely require health maintenance activities. However, these health conditions associated with ageing cause elderly people to seek treatment so as to address their ailments and maintain good health status and wellbeing. [2] The importance of seeking health care in later life has been highlighted in previous studies. $\frac{[8,9]}{}$ ascertained that obtaining data about health seeking behaviour among the elderly people is important for developing appropriate social and health policies. In the same vein,[9] emphasized that health seeking behaviour has been shown to reduce uncertainty and anxiety of patients.

In recent times, evidences have shown that health seeking behaviour is potentially and independently determined by myriads and multifaceted individual demographic, institutional, socioeconomic, and systemic factors (including educational level, income, urbanity/rurality, religion, social support networks, health status, trust, and the political economy of health and healthcare) and also the orientations of health system response. $[8,10,11,12,13]$ Elderly individuals have been found to seek for treatment from different sources including pharmacist, healthcare providers, retired community staff, friends and relatives, internet, radio, and television stations. $[2,8]$

Although studies in the past have focused on the concept of health information-seeking behaviour among older people globally, $[8,11,14]$ subjective views of the elderly people who are not economically buoyant on possible factors that influence their health seeking behavior still remain scant in Nigeria. Notwithstanding, few studies had examined the utilization of health centers in Nigeria by older people. $[3,15]$ We are however, interested in health seeking behaviour among elderly people who are poor and the correlates with their health status in Nigeria. Therefore, this study is of paramount necessity as it explores the most economically vulnerable elderly groups in Nigeria thereby filling an important significant knowledge gap in literature. This study has useful policy implication: firstly, the findings of this study will assist in the development and design of more integrative and effective policy instruments to remove hurdles encountered by elderly people when seeking for health treatment in healthcare centers. Secondly, understanding the health seeking behavioural pattern especially among the poor elderly people in Nigeria will be of help to the health actors in their efforts towards improving elderly people's access to quality health facilities and lastly, an in-depth research on health seeking behavior among the poor elderly people is critical in understanding how elderly people seek for health treatment in later life.

\section{MATERIAL AND METHODS}

\section{Study design and settings}

The study was conducted among the elderly people in Osun State, Nigeria employing quantitative method of data collection. Osun State was chosen because of her relative high number of elderly people in the State [16]. A cross-sectional design involving quantitative 
Annals of International Medical and Dental Research

E-ISSN: 2395-2822 | P-ISSN: 2395-2814

Vol-8, Issue-2 | March-April 2022

DOI: 10.53339/aimdr.2022.8.2.9

Page no- 52-62 | Section- Research Article (Public Health)

strands of research was used for the study. Elderly people were defined as persons of 60 years or more. The population of Osun was estimated at 3,416,959 people with elderly people aged 60+ years taking about 201,480 people (5.89\%).[16] The elderly people who are people are people who spend less than a dollar per day and were used for the purpose of this study where we investigated their health seeking behavior in the area. Health facilities level in Osun state comprised of primary, secondary and tertiary facilities level. Ownership of health facilities comprised public and private ownership. Health services available and being provided in hospitals in Osun State include medical services, surgical services, obstetrics and Gynecology services, pediatrics services, dental services and specific clinical services.

\section{Participants and recruitment procedures}

In this study, we conceptualized the public healthcare facilities as non-profit healthcare facilities that are funded, operated and supervised by the government, where private health facilities were defined as profit-oriented healthcare facilities that are funded, owned and operated by private individuals or organisations. We adopted a multistage sampling procedure for the process of selection of the respondents. The Ife East, Atakumosa West and Obokun local governments have 10, 11 and 10 wards, respectively. Respondents were sampled from two-fifths of the wards following guidelines from the World Health Organization (WHO) sampling manual. Thus, four wards each were used to recruit the respondents. In each Local government area, the sample size of 433 was divided by the randomly selected number of enumerated areas to determine the average number of respondents to recruit from each EA. A total of 48 Enumeration areas were used and elderly recruited from 433 households

The research instruments consisted of a structured questionnaire which was divided into four sections. The first section (Section A) elicited information about the respondents' socio-demographic characteristics, the second section (Section B) assessed the Health status of the respondents' using SF 36, the third section (Section C) determined their morbidity pattern while the last section (Section D) sought information on the respondents' health seeking practices using a 13 item self-developed questionnaire. The instrument was translated to Yoruba language for Non- English speaking respondents using back to back translation. The 13 item questions were scored and 54ategorized into good and poor health seeking behaviour. The scoring was based on a scale of 1 and 2 i.e. a Yes option $=2$ while a No option $=1$. The total possible score was between 13 and 26 and scores above and below. The mean score was considered "good" and "poor" health seeking behaviour, respectively. The data was collected electronically through the administration of the interviewer research instrument to the respondents at their various locations. A pilot study was conducted among elderly people in Ede South Local Government Area, Osun State. The result of the test-retest showed that the instrument was internally consistent and had a good reliability value. Data computed were transferred into an analytical software SPSS version 23 and were subjected to both inferential and descriptive statistics. 
Annals of International Medical and Dental Research E-ISSN: 2395-2822 | P-ISSN: 2395-2814

Vol-8, Issue-2 | March-April 2022

DOI: 10.53339/aimdr.2022.8.2.9

Page no- 52-62 | Section- Research Article (Public Health)

\section{Ethical approval and consent to participate}

Ethical approval was granted by the Committee on Research Publication and Ethics, department of nursing science, Obafemi Awolowo University, Ile-Ife, Nigeria. The purpose of the study was explicitly explained to the participants of the study before their informed verbal consent was obtained. In addition, the study participants were assured of strict confidentiality and anonymity of the information they provided. They were further assured that their participation in the study was voluntary. Therefore, they were free to opt-out at any time.

\section{RESULTS}

\section{Respondents' characteristics}

[Table 1] shows the characteristics of the 433 respondents where about $60.5 \%$ of the sampled respondents were of the female gender, about $52.0 \%$ were within the age range of $60-69$ years with a mean age of 72 years. With respect to their duration of residing in the area, majority of the respondents $(46.7 \%)$ have been living in the areas for 30 years or more.
Majority $(55.7 \%)$ of the respondents were married while $39.7 \%$ of the respondents had no formal education. With regards to living condition, only $19.6 \%$ were living alone, majority $(77.6 \%)$ of the respondents were found to be self-employed. With respects to their average monthly income, about $39.7 \%$ of the respondents reported that they were earning less than 10,000 naira.

\section{Health Status of respondents}

In [Figure 1], it is evident that majority of the respondents had poor health status. It was found that $67.4 \%$ respondents had poor physical functioning, $49.0 \%$ of respondents were being faced with role limitation due to physical health, $53.3 \%$ of them facing role limitation due to emotional problem, 66.5\% were facing energy/fatigue problem, $60.0 \%$ are being faced with emotional well-being, $67.4 \%$ with social functioning, $72.7 \%$ were facing bodily pain and $97.0 \%$ of the respondents were faced with the general health problem. The overall health status of the respondents was poor.

Table 1: Socio-Demographic Characteristics of Respondents $(n=433)$

\begin{tabular}{|l|c|c|}
\hline Variable & Frequency & Percentage \\
\hline Age range (in years) Mean age $=72$ years & & \\
\hline $60-69$ & 225 & 52.0 \\
\hline $70-79$ & 115 & 26.6 \\
\hline $80+$ & 93 & 21.5 \\
\hline Duration of residing in the area (in years) & & 39.0 \\
\hline$<10$ & 169 & 7.9 \\
\hline $10-19$ & 34 & 6.5 \\
\hline $20-29$ & 28 & 46.7 \\
\hline $30+$ & 202 & \\
\hline Sex & & 39.5 \\
\hline Male & 171 & 55 \\
\hline
\end{tabular}

Copyright: @The author(s), published in Annals of International Medical and Dental Research, Vol-8, Issue-2. This is an open access article under the Attribution-Non Commercial 2.0 Generic (CC BY-NC 2.0) license. (https://creativecommons.org/licenses/by-nc/2.0/) 
Annals of International Medical and Dental Research

E-ISSN: 2395-2822 | P-ISSN: 2395-2814

Vol-8, Issue-2 | March-April 2022

DOI: 10.53339/aimdr.2022.8.2.9

Page no- 52-62 | Section- Research Article (Public Health)

\begin{tabular}{|l|c|c|}
\hline Female & 262 & 60.5 \\
\hline Marital status & & 55.7 \\
\hline Currently married & 241 & 44.3 \\
\hline Widowed & 192 & 39.7 \\
\hline Level of Education & & 31.9 \\
\hline No formal education & 172 & 23.1 \\
\hline Primary & 138 & 5.3 \\
\hline Secondary & 100 & \\
\hline Post-secondary & 23 & 2.8 \\
\hline Employment status & & 7.6 \\
\hline Employed & 12 & 77.6 \\
\hline Not employed & 33 & 12.0 \\
\hline Self employed & 336 & \\
\hline Retired & 52 & 19.6 \\
\hline Living condition & & 32.3 \\
\hline Living alone & 85 & 25.2 \\
\hline Living with my spouse & 140 & 22.9 \\
\hline living with my children & 109 & \\
\hline living in the family compound & 99 & 12.7 \\
\hline Income & & 39.7 \\
\hline No income & 55 & 24.2 \\
\hline <\#10000 & 172 & 9.9 \\
\hline$\# 10000-\# 19000$ & 105 & \\
\hline$\# 20000-\# 29000$ & 58 & \\
\hline$>\# 30000$ & 43 & \\
\hline
\end{tabular}

\section{Health Seeking Behaviour of respondents}

The results of the health seeking behavior among the respondents were presented in Table 2. It was revealed that majority $(72.7 \%)$ of respondents were comfortable visiting health centre when sick, $69.5 \%$ preferred visiting health centre for treatment when sick, $42.5 \%$ visited health centre within 24 hours when sick, 37.4\% engaged in regular exercise, $55.4 \%$ claimed there were enough health services provided, $73.7 \%$ claimed that health centre was within their reach, $79.7 \%$ were not neglected whenever they visited medical centre for treatment, 57.7\% did not visit traditional healers for treatment when sick, $72.3 \%$ utilized more service of a medical personnel than caregiver, $71.4 \%$ were able to utilise health care services regardless of the distance, $61.9 \%$ were able to utilize health care service regardless of its high cost, $71.1 \%$ preferred medical centre than home service whenever they needed medical attention and $79.0 \%$ could afford transportation fee to visit the medical centre. Therefore, results showed that majority (71.4\%) of respondents had good health seeking behaviour as majority of them utilised more service of a medical personnel. 
Annals of International Medical and Dental Research

E-ISSN: 2395-2822 | P-ISSN: 2395-2814

Vol-8, Issue-2 | March-April 2022

DOI: 10.53339/aimdr.2022.8.2.9

Page no- 52-62 | Section- Research Article (Public Health)

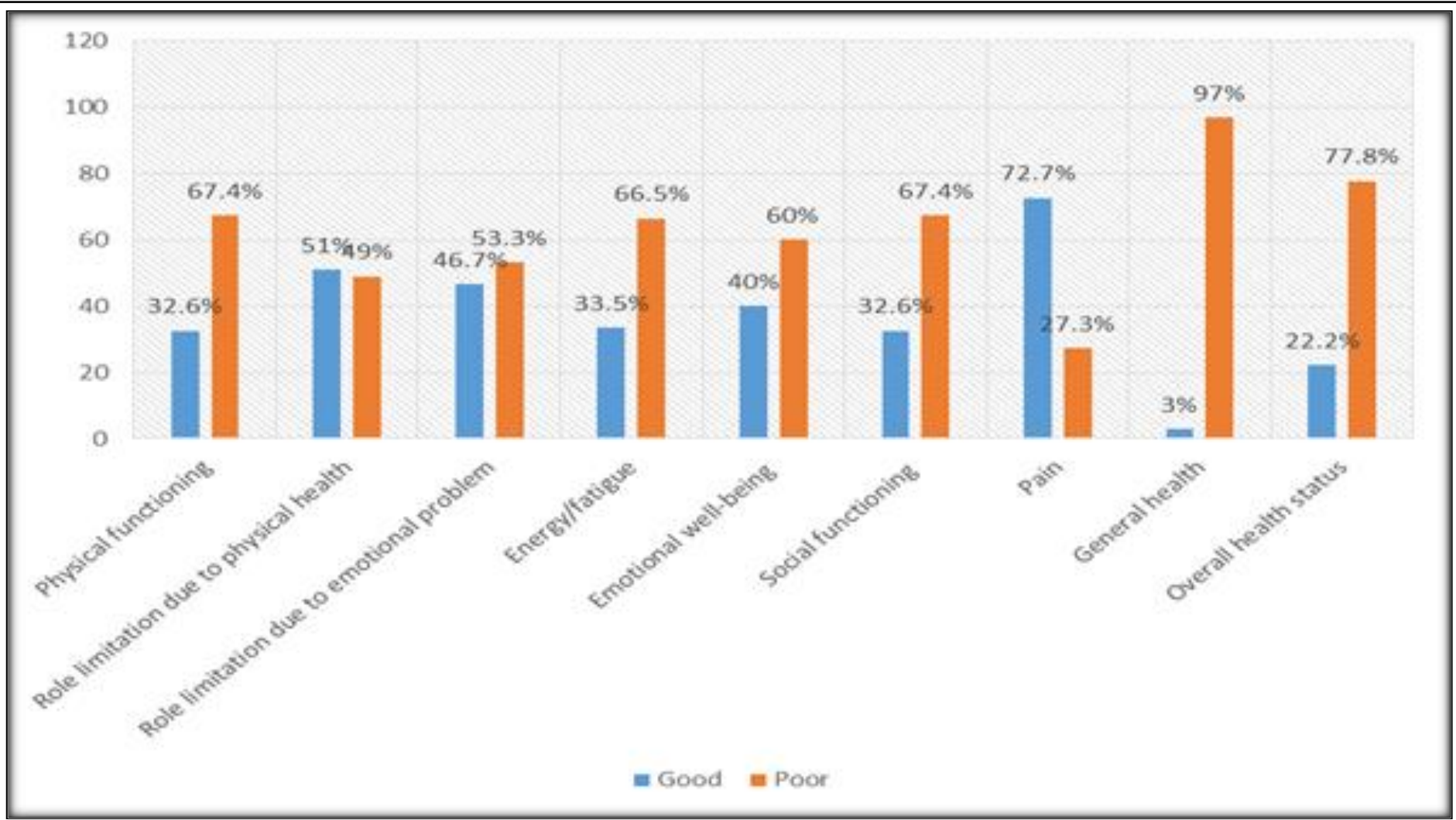

Figure 1: Distribution of respondents by health status

Table 2: Distribution of respondents by health seeking behaviour

\begin{tabular}{|c|c|c|}
\hline Behaviour & Yes $(\%)$ & No $(\%)$ \\
\hline I am comfortable visiting health centre when I am sick. & $315(72.7)$ & $118(27.3)$ \\
\hline I prefer visiting health centre for treatment when I am sick. & $301(69.5)$ & $132(30.5)$ \\
\hline I visit health centre within 24 hours when am sick & $184(42.5)$ & $249(57.5)$ \\
\hline I engage in regular exercise & $162(37.4)$ & $271(62.4)$ \\
\hline There is enough Health services provided. & $240(55.4)$ & $193(44.6)$ \\
\hline The health centre is within my reach. & $319(73.7)$ & $114(26.3)$ \\
\hline I am not neglected whenever I visit medical centre for treatment. & $345(79.7)$ & $88(20.3)$ \\
\hline I do not visit traditional healers for treatment when sick. & $250(57.7)$ & $183(42.3)$ \\
\hline I utilize more service of a medical personnel than caregiver. & $313(72.3)$ & $120(27.7)$ \\
\hline I am able to utilise health care services regardless of the distance & $309(71.4)$ & $124(28.6)$ \\
\hline I am able to utilize health care service regardless of its high cost. & $268(61.9)$ & $165(38.1)$ \\
\hline $\begin{array}{l}\text { I prefer medical centre than home service whenever I need medical } \\
\text { attention. }\end{array}$ & $308(71.1)$ & $125(28.9)$ \\
\hline I can afford transportation fee to visit medical centre. & $342(79.0)$ & $9121.0)$ \\
\hline
\end{tabular}


Annals of International Medical and Dental Research E-ISSN: 2395-2822 | P-ISSN: 2395-2814

Vol-8, Issue-2 | March-April 2022

DOI: 10.53339/aimdr.2022.8.2.9

Page no- 52-62 | Section- Research Article (Public Health)

\section{Relationship between health status, morbidity pattern and health seeking behaviour}

[Table 3] presents the results of binary logistic regression analysis performed to examine the relationship between health status, morbidity pattern as well as health seeking behaviour of the elderly. The independent variables were the list of diseases to measuring morbidity and health seeking behaviour and the outcome variable was health status of the elderly using poor health status as base outcome. The model revealed that, none of the diseases had statistically significant effect on the elderly's health status. Elderly people with good health seeking behaviour were less likely to have poor health status with a reduced odd of (OR: 0.775)

Table 3: Binary logistic regression showing the relationship between health status, morbidity pattern and health seeking behaviour

\begin{tabular}{|l|l|l|l|l|l|}
\hline & Odds ratio & Std. Err. & P>z & \multicolumn{2}{l|}{ [95\% Conf. Interval] } \\
\hline Joint pain/arthritis & 1.217 & 0.427 & 0.574 & 0.612 & 2.422 \\
\hline High blood pressure & 0.487 & 0.226 & 0.123 & 0.195 & 1.214 \\
\hline Diabetes & 0.314 & 0.347 & 0.295 & 0.0361 & 2.744 \\
\hline Poor eyesight & 0.822 & 0.306 & 0.600 & 0.397 & 1.705 \\
\hline Heart problems & 0.799 & 0.758 & 0.814 & 0.124 & 5.136 \\
\hline Loss of hearing & 0.364 & 0.273 & 0.179 & 0.083 & 1.586 \\
\hline Paralysis & 1.021 & 0.221 & 0.337 & 0.342 & 3.154 \\
\hline Skin infections & 1.120 & 0.230 & 0.275 & 0.254 & 1.264 \\
\hline Kidney problem & 3.950 & 6.571 & 0.409 & 0.151 & 10.971 \\
\hline Health seeking behaviour & 0.775 & 0.309 & 0.524 & 0.354 & 1.694 \\
\hline (cons) & 0.671 & 0.203 & 0.188 & 0.371 & 1.215 \\
\hline
\end{tabular}

\section{Relationship between socio-demographic characteristics and health status of elderly}

Presented in Table 4 is the result of chi-square analysis showing the interaction between sociodemographic characteristics and the health status of the elderly people in Osun State. The result showed that age, marital status, educational status and monthly income were found to be statistically associated with the health status among the elderly as $\mathrm{p}$-values less than $0.05(\mathrm{p}<0.05)$.

Table 4: Result of chi-square analysis showing relationship between socio-demographic characteristics and health status of elderly in Osun State

\begin{tabular}{|l|l|l|l|l|l|}
\hline \multirow{2}{*}{ Characteristics } & Health status & Total (\%) & \multirow{2}{*}{ p-value } \\
\cline { 2 - 4 } & Poor n(77.8) & Good n(22.2) & & \multirow{2}{*}{11.686} & \multirow{2}{*}{$0.003^{*}$} \\
\hline Age group (in years) & & & & \\
\hline $60-69$ & $171(76.0)$ & $118(44.7)$ & $225(100.0)$ & \\
\hline $70-79$ & $82(71.3)$ & $59(58.4)$ & $115(100.0)$ & & \multirow{2}{*}{0.061} \\
\hline $80+$ & $84(90.3)$ & $27(40.3)$ & $93(100.0)$ & & \\
\hline Gender & & & & & \\
\hline Male & $141(82.5)$ & $30(17.5)$ & $171(100.0)$ & 3.506 & \\
\hline
\end{tabular}


Annals of International Medical and Dental Research E-ISSN: 2395-2822 | P-ISSN: 2395-2814

Vol-8, Issue-2 | March-April 2022

DOI: 10.53339/aimdr.2022.8.2.9

Page no- 52-62 | Section- Research Article (Public Health)

\begin{tabular}{|c|c|c|c|c|c|}
\hline Female & $196(74.8)$ & $66(25.2)$ & $262(100.0)$ & & \\
\hline Marital status & & & & \multirow[b]{3}{*}{16.738} & \multirow[b]{3}{*}{$0.000 *$} \\
\hline Currently married & $170(70.5)$ & $71(29.5)$ & $241(100.0)$ & & \\
\hline Widowed & $167(86.9)$ & $25(13.0)$ & $192(100.0)$ & & \\
\hline \multicolumn{4}{|l|}{ Educational status } & \multirow{5}{*}{8.721} & \multirow{5}{*}{$0.033 *$} \\
\hline No formal education & $143(83.1)$ & $29(16.9)$ & $172(100.0)$ & & \\
\hline Primary & $109(78.9)$ & $29(21.0)$ & $138(100.0)$ & & \\
\hline Secondary & $68(68.0)$ & $32(32.0)$ & $100(100.0)$ & & \\
\hline Tertiary & $17(73.9)$ & $6(26.0)$ & $23(100.0)$ & & \\
\hline \multicolumn{4}{|l|}{ Employment status } & \multirow{5}{*}{15.828} & \multirow{5}{*}{$0.001 *$} \\
\hline Employed & $7(58.3)$ & $5(41.7)$ & $12(100.0)$ & & \\
\hline Not employed & $31(93.9)$ & $2(6.1)$ & $33(100.0)$ & & \\
\hline Self employed & $251(74.7)$ & $85(25.3)$ & $336(100.0)$ & & \\
\hline Retired & $48(92.3)$ & $4(7.7)$ & $52(100.0)$ & & \\
\hline \multicolumn{4}{|l|}{ Living condition } & \multirow{5}{*}{ (3), 2.086} & \multirow{5}{*}{0.555} \\
\hline Living alone & $68(80.0)$ & $17(20.0)$ & $85(100.0)$ & & \\
\hline Living with my spouse & $107(76.4)$ & $33(23.6)$ & $140(100.0)$ & & \\
\hline Living with my children & $81(74.3)$ & $28(25.7)$ & $109(100.0)$ & & \\
\hline $\begin{array}{l}\text { Living in the family } \\
\text { compound }\end{array}$ & $81(81.8)$ & $18(18.2)$ & $99(100.0)$ & & \\
\hline \multicolumn{6}{|l|}{ Monthly income (in naira) } \\
\hline No income & $53(96.4)$ & $2(3.6)$ & $55(100.0)$ & \multirow{5}{*}{$(4), 27.354$} & \multirow{5}{*}{$0.000 *$} \\
\hline Less than 10000 & $143(83.1)$ & $29(16.9)$ & $172(100.0)$ & & \\
\hline $10000-19000$ & $72(68.6)$ & $33(31.4)$ & $105(100.0)$ & & \\
\hline $20000-29000$ & $36(62.1)$ & $22(37.9)$ & $58(100.0)$ & & \\
\hline 30000 and above & $33(76.7)$ & $10(23.3)$ & $43(100.0)$ & & \\
\hline
\end{tabular}

\section{DISCUSSION}

This study explored the correlates between the health seeking behavior and health status of elderly people using empirical evidence from Osun State, Nigeria. We found that elderly people in Osun State generally has a poor health status with larger proportion of them having health issues including poor physical functioning, role limitations due to physical health and emotional problems, energy/fatigue, poor emotional well-being, impaired social functioning and bodily pains. This implies that health problems that accompanied old age is more prevalent among the elderly people in Osun State causing their health to deteriorate. This result is in agreement with in their work on health seeking behavior among adults and elderly with chronic health condition(s) who found that considerable proportions of the elderly people in low and middle income countries (LMICs) suffered from chronic health condition. [17] In addition,[18] in their work on multimorbidity and health seeking behaviours among older people in Myanmar: A community survey found that considerable proportions of the elderly people reported at least one chronic 
Annals of International Medical and Dental Research

E-ISSN: 2395-2822 | P-ISSN: 2395-2814

Vol-8, Issue-2 | March-April 2022

DOI: 10.53339/aimdr.2022.8.2.9

Page no- 52-62 | Section- Research Article (Public Health)

condition with about $33.2 \%$ reporting two or more conditions (multimorbidity). This is an indication that ageing is associated with both intrinsic and extrinsic changes as well as health problems with varying levels of disability and limitations in functionality. Although chronic diseases may occur at any stage in life, these are more common in old age. ${ }^{[5]}$ made findings in their study that showed that most of the patients presented with chronic diseases. This is similar to reports of studies among older persons in Low to Middle Income Countries (LMIC), which has been reported to be the trend in many LMICs and expected in this age group. On a similar note,[7] in their work on self-care practices and health-seeking behavior among older persons in a developing country also found that health related issues is more prevalent among the older adults who faces health challenges such as strokes induced by hypertension. They insinuated that hypertension phenomenon is the same globally but the factors causing it may vary according to countries.

Another important finding in this study is that majority of the elderly people sample has a good health seeking behavior. For example, majority of them preferred visiting health center for treatment whenever they are sick. Also, this elderly people were found to utilized health care service of a medical personnel than care giver and preferred medical center than home service whenever they need medical attention. All of this is an indication that elderly people in Osun State has a good health seeking behavior although might not total correspond to a good health status. This might be due to the fact that when they are diagnosed of health challenges at the health center, they might not be able to afford the treatment because of their poor financial status, thus they tend to return home in many cases without receiving treatment thus leading to deteriorating and poor health status. This finding however disagreed with who found that even though health centers are conducted in the middle of the community and free of charge, [7] more than half of respondents did not visit regularly. They found that risk factors deterring people from visiting HCs included high self-efficacy and not wanting the information and their health complaints related significantly with their health-seeking behaviour.

Other key findings from this study was that some socioeconomic variables were found to be associated with health status of elderly people in Osun State. For example, it was found that age, marital status, education status and monthly income statistically affect their health status. People who are of old age tend to experience some health challenges that accompanied old age thus affecting their health status. Furthermore, education status of the elderly people tend to influence their health status. Elderly people who are illiterate might find it difficult to use the available health centers due to their inadequate knowledge on the usefulness of health centers on getting proper treatment. This has been reported by many studies including that education significantly influenced health seeking behavior among the older people thus influencing their health status. $[2,17,18]$ Income which coincide with the purchasing power of the elderly people was also found to significantly influenced their health status. Poverty especially in LMICs in Africa has been 
Annals of International Medical and Dental Research

E-ISSN: 2395-2822 | P-ISSN: 2395-2814

Vol-8, Issue-2 | March-April 2022

DOI: 10.53339/aimdr.2022.8.2.9

Page no- 52-62 | Section- Research Article (Public Health)

found to be a major barrier to seeking treatment among the older people whenever they are sick.[2]

\section{CONCLUSIONS}

An adequate understanding of health seeking behaviour and its correlates with health status especially among the elderly people is needed to improve the health care in Nigeria. We found that although the elderly people have a good health seeking behaviour, it does not however translate to good health status. Therefore, strategies to improve the health status including improving their financial status should be developed with adequate health literacy. Elderly people should learn the importance of regular health examinations to promote health, prevent diseases, and slow the progress of chronic diseases. An intervention program should be developed to increase the

\section{REFERENCES}

1. Umberson D, Montez JK. Social relationships and health: a flashpoint for health policy. J Health Soc Behav. 2010;51 Suppl(Suppl):S54-S66. doi:10.1177/0022146510383501

2. Agyemang-Duah W, Arthur-Holmes F, Peprah C, Adei D, Peprah P. Dynamics of health informationseeking behaviour among older adults with very low incomes in Ghana: a qualitative study. BMC Public Health.

2020;20:928 https://doi.org/10.1186/s12889-020-08982-1

3. Latunji OO, Akinyemi OO. Factors Influencing Health-Seeking Behaviour among Civil Servants in Ibadan, Nigeria. Ann Ibd Pg Med. 2018;16(1): 52-60.

4. Adebusoye LA, Ladipo MM, Owoaje ET, Ogunbode AM. Morbidity pattern amongst elderly patients presenting at a primary care clinic in Nigeria. Afr J Prim Health Care Fam Med. 2011;3(1):211. https://dx.doi.org/10.4102\%2Fphcfm.v3i1.211 number of health care centers that are affordable to the elderly people.

\section{Acknowledgements}

To God alone be the glory, honour and adoration for seeing me through the course of this study despite all the challenges and rigours. Special appreciation goes to my supervisor in person of Dr Joel Faronbi, for your timely response and tutelage and to the Head of Department, Nursing Prof Mrs Omolola Irinoye and other faculty members. My profound gratitude goes to my husband, children, parents and my siblings for your support and cooperation. Special thanks to members of staff of Centre for Distance Learning, OAU especially the Head of Department Medical Unit Dr D.E Oyebola and other medical unit member.

5. Cadmus EO, Adebusoye LA, Olowookere OO, Oluwatosin OG, Owoaje ET, Alonge TO. A descriptive study of the morbidity pattern of older persons presenting at a Geriatric Centre in Southwestern Nigeria. Niger J Clin Pract. 2017;20(7):873-878. doi: 10.4103/njcp.njcp_362_16.

6. Baral R, Sapkota P. Health Seeking Behaviour among Elderly People of Bharatpur Municipality of Chitwan District, Nepal. JCMS Nepal. 2018;14(3):150-153.

https://doi.org/10.3126/jcmsn.v14i3.21178

7. Irwan AM, Kato M, Kitaoka K, Kido T, Taniguchi Y, Shogenji M. Self-care practices and health-seeking behavior among older persons in a developing country: Theories-based research. Int J Nurs Sci. 2016; 3:11-23.

8. Chaudhuri S, Le T, White C, Thompson H, Demiris G. Examining health information-seeking Behaviours of older adults. Comput Inform Nurs. 2013; 
Annals of International Medical and Dental Research

E-ISSN: 2395-2822 | P-ISSN: 2395-2814

Vol-8, Issue-2 | March-April 2022

DOI: 10.53339/aimdr.2022.8.2.9

Page no- 52-62 | Section- Research Article (Public Health)

https://dx.doi.org/10.1097\%2F01.NCN.0000432131 .92020 .42

9. Feltwell AK, Rees CE. The information-seeking behaviours of partners of men with prostate cancer: a qualitative pilot study. Patient Educ Couns. 2004;54(2):179-85. doi: 10.1016/S07383991(03)00212-X.

10. Shi HJ, Nakamura K, Takano T. Health values and health-information-seeking in relation to positive change of health practice among middle-aged urban men. Prev Med. 2004;39(6):1164-71. doi: 10.1016/j.ypmed.2004.04.030.

11. Musoke D, Boynton P, Butler C, Musoke MB. Health seeking behaviour and challenges in utilising health facilities in Wakiso district, Uganda. Afr Health Sci. 2014;14(4):1046-1055. doi:10.4314/ahs.v14i4.36

12. Rees CE, Bath PA. Information-seeking behaviours of women with breast cancer. Oncol Nurs Forum. 2001;28:899-907.

13. Tucker CA, Martin MP, Jones RB. Health information needs, source preferences and engagement behaviours of women with metastatic breast cancer across the care continuum: protocol for a scoping review. BMJ open. 2017;7(2):e013619. https://doi.org/10.1136/bmjopen-2016-013619.
14. Manafo E, Wong S. Exploring older adults' health information seeking behaviors. J Nutr Educ Behav. 2012;44(1):85-9. doi: 10.1016/j.jneb.2011.05.018.

15. Atchessi N, Ridde V, Abimbola S, Zunzunegui MV. Factors associated with the healthcare-seeking behaviour of older people in Nigeria. Arch Gerontol Geriatr. 2018;79:1-7.

doi: 10.1016/j.archger.2018.07.015.

16. Kim IH, Kisseleva T, Brenner DA. Aging and liver disease. Curr Opin Gastroenterol. 2015;31(3):184191. doi:10.1097/MOG.0000000000000176

17. Gabrani J, Schindler C, Wyss K. Health Seeking Behavior Among Adults and Elderly With Chronic Health Condition(s) in Albania. Front Public Health. 2021;9:616014. doi: 10.3389/fpubh.2021.616014.

18. Aye SKK, Hlaing HH, Htay SS, Cumming R. Multimorbidity and health seeking behaviours among older people in Myanmar: A community survey. PLoS ONE. 2019;14(7):e0219543. https://doi.org/10.1371/journal.pone.0219543

Source of Support: Nil, Conflict of Interest: None declared 